\title{
An Intelligent Maintenance System for Continuous Cost-Based Prioritisation of Maintenance Activities
}

\author{
W.J. Moore and A.G. Starr \\ Through Life Support Research Group, \\ School of Mechanical, Aerospace and Civil Engineering, \\ The University of Manchester, Manchester, M60 1QD, UK.
}

\begin{abstract}
A key aspect of competition in industrial maintenance is the trade-off between cost and risk. Decision making is dependent upon up-to-date information about distributed and disparate plant, coupled with knowledge of sensitive non-technical issues. Enabling technologies such as the internet are making strides in improving the quantity and quality of data, particularly by improving links with other information systems. In maintenance, the problem of disparate data sources is important. It is very difficult to make optimal decisions because the information is not easily obtained and merged. Information about technical state or machine health, cost of maintenance activities or loss of production, and non-technical risk factors such as customer information, is required. Even in the best information systems, these are not defined in the same units, and are not presented on a consistent time scale; typically, they are in different information systems. Some data is continuously updated, e.g. condition data, but the critical risk information is typically drawn from a historical survey, fixed in time.

A particular problem for the users of condition based maintenance is the treatment of alarms. In principle, only genuine problems are reported, but the technical risk of failure is not the full story. The decision-maker will take into account cost, criticality and other factors, such as limited resources, to prioritise the work. The work reported here automatically prioritises jobs arising from condition based maintenance using a strategy called Cost-Based Criticality (CBC) which draws together three types of information. CBC weights each incident flagged by condition monitoring alarms with up-to-date cost information and risk factors, allowing an optimised prioritisation of maintenance activities. CBC does not attempt to change the strategic plan for maintenance activities: it only addresses prioritisation. The strategy uses a thin-client architecture rather than a central database, and is illustrated with examples from food manufacturing.
\end{abstract}

Keywords: Maintenance engineering, condition monitoring, alarms, criticality analysis, emaintenance, intelligent systems. 


\section{Introduction}

To succeed in the competitive global marketplace of today, it is vital for an organisation to optimise its operational costs. The cost of maintaining complex industrial systems is one of the critical factors influencing the enterprise operating costs and it is estimated that $18-30 \%$ of this is wasted $[1,2]$. Hence, the importance of optimising the maintenance function is obvious.

Inadequate maintenance can result in higher levels of unplanned asset failure, which has many inherent costs to the organisation including:

- lost production;

- rework;

- scrap;

- labour;

- spare parts;

- fines for late orders;

- lost orders due to unsatisfied customers.

The nature of maintenance planning is changing rapidly with the uptake of condition based maintenance, integration and e-maintenance.

\subsection{Condition based maintenance}

Condition based maintenance aims to reduce the number of unplanned asset failures by monitoring equipment condition to predict failures enabling remedial actions to be taken. It includes, but is not limited to, technologies such as:

- vibration analysis;

- infrared thermography;

- oil analysis and tribology;

- ultrasonics;

- motor current analysis;

- performance monitoring;

- visual inspection.
Many Computerised Maintenance Management Systems (CMMS) use condition monitoring alarm levels to trigger maintenance activities. Incoming conditionbased data for assets is compared to predefined thresholds and when the threshold is exceeded an alarm is raised to highlight the event. The quantity of condition monitoring activity, coupled with limitations in setting alarm levels, has led to a problem for maintenance personnel coping with the quantity of alarms on a daily basis. The human decision-maker must assume that the alarms are true until it is proved otherwise. Determining which of the alarms to tackle first can be a difficult and time consuming procedure and is usually reliant on the experience of the operator.

\subsection{Integration of criticality}

Criticality assessments are procedures which aim to identify those assets that could have the greatest effect on an operation if they were to fail. When deciding on which maintenance strategies to adopt, organisations usually carry out some form of criticality assessment based on collected data or the experience of personnel. However, once a strategy has been adopted it is unlikely that the results of the analysis will be used to prioritise activities on a daily basis. Most criticality assessments are only readily available on paper.

Resource for repair and replacement arising from an alarm is limited. Focus of resource requires accurate information to prioritise maintenance activities and hence optimise return on investment. Forward thinking plant executives, maintenance managers and work planners have always wanted to have information about the condition of equipment assets at their fingertips when they need it. Unfortunately, this information is usually scattered among separate information systems making it difficult or impossible to view on one computer 
terminal and use as a basis for sound asset management decisions [3].

Integration in information systems provides a potential solution to the problem of isolated data sources. Decision making is often achieved with uncertainty and unknowns, while measuring against conflicting performance criteria. Maintenance decisions are made in the context of business priorities. Integration must facilitate the bi-directional flow of data and information into the decision-making and planning process at all levels. This reaches from business systems right down to sensor level. Integrated systems should automate the retrieval of information that decision makers require to make sound judgements. Essentially it should be a means of establishing links between data sources and close the loop from the minutiae of data to collection to strategic decision making [4].

\section{3 e-Maintenance}

e-Maintenance brings benefits to a distributed organisation, that is where plant, people, expertise or data are physically separate or isolated. Baldwin defines emaintenance as an "asset information management network that integrates and synchronises the various maintenance and reliability applications to gather and deliver asset information where it is needed when it is needed" [3]. A more general definition is that e-maintenance is a "maintenance management concept whereby assets are monitored and managed over the Internet" [5].

The e-maintenance infrastructure is considered to be made up of several information sectors. These are:

- control systems and production schedulers;

- engineering product data management systems;
- enterprise resource planning (ERP) systems;

- condition monitoring systems;

- maintenance scheduling (CMMS/ EAM) systems;

- plant asset management (PAM) systems. [3]

\subsection{Aims and objectives}

This paper will illustrate the problems experienced by a human decision-maker trying to cope with condition monitoring alarms. The aim of the work is to create a method to focus attention automatically on alarms that pose the gravest consequences to the business. The methods and functionality of criticality assessments will be reviewed. The nature of distributed data will be considered and the benefits arising from emaintenance will be explored.

On-line criticality is an important input to the process. Typical criticality analyses (FMECA etc) have been done, but remain on paper. The model of the layout of the plant varies with the product in the case study company. In this work the criticality model will be live and the choice of product affects the numbers used for criticality as an input to $\mathrm{CBC}$. The main purpose of the $\mathrm{CBC}$ algorithm is to rank all the alarms arising from condition monitoring. We observe that the alarms can be trusted in mature applications but that they are not all equally important and we do not have the resources to do all the jobs.

The objectives of the paper are:

- to review and understand the limitations of disparate and fragmented data in the decisionmaking process;

- review the key features of methods for integration and fusion in maintenance decision data; 
- to illustrate an automated algorithm for dynamically merging maintenance data streams;

- to demonstrate effectiveness by implementing the algorithm on industrial data.

\section{Prioritising Maintenance Activities}

\subsection{Condition-Based Alarms}

The prioritisation of maintenance activities has become increasingly difficult due to the complexity of modern organisational facilities and advancements in condition monitoring techniques. The automation of data collection, processing and analysis has increased the quantity of information available without necessarily improving its quality. At the same time, the availability of skilled personnel is tightened as businesses strive to become more competitive.

Computerised Maintenance Management Systems (CMMS) have made extensive use of condition-based data for their scheduling of maintenance actions. The state of health of a machine or process is estimated by analysis of measured parameters. Typically, the parameter is compared to a predefined threshold, and the CMMS automatically compares incoming data to a look-up table of alarm levels. If a threshold is broken then an alarm is raised to highlight the event and trigger actions to resolve the issue. However, this approach has a number of drawbacks:

- the initial setting has no historical data, so a heuristic approach may be used - this relies on the expertise to interpret standards or to draw on experience of similar machines;

- there is no adaptation to running conditions, e.g. load or speed;

- manual review is laborious and is often not done [6].
This simplistic approach to alarm setting results in many false alarms being generated, which further complicates the task of scheduling maintenance activities. Attention must be focused on those alarms that may have the gravest effect on the profitability of the organisation.

To determine this, the maintenance manager must be able to balance the cost of performing maintenance activities against the cost of not performing them. Performing this task effectively and consistently involves the consideration of many factors and an in-depth knowledge of the business. In reality, it is almost impossible due to the number of factors that require consideration and the number of assets that it must be applied to. It has been proved that "an individual cannot compare simultaneously more than seven objects (plus or minus two) without becoming more and more inconsistent" [7].

A real dilemma is the dependence of a process, and essentially an organisation, on an individual's expert knowledge of a plant: what happens if they are sick, or worse, leave? This would suggest that a more appropriate, systematic and adaptive process is required to effectively prioritise maintenance activities.

\subsection{Criticality Analysis}

There are numerous methods currently available to maintenance managers to assist them in targeting those assets that are most critical to the department. One of the most popular and widely used methods is 'Failure Modes, Effects and Criticality Analysis'. FMECA is a bottom-up approach that ranks assets in order of priority by determining the consequences, probabilities, and in some cases, the likelihood of detecting asset failures.

There is no standard method of attributing a value to each of these factors and many organisations have developed their own 
bespoke classification tables such as Table 1 [8]. Others assign a value between one and ten to each factor and multiply these together to obtain a 'Risk Priority Number' (RPN) which is used to rank the assets.

The significance of these classifications or RPN numbers is questionable due to the subjective nature of their generation. The values assigned to each weighting factor are drawn from a table that crudely attempts to convert qualitative data into quantitative data using the experience of personnel or with the assistance of an external consultant. This approach can be very valuable to a maintenance function but it has many weaknesses as identified below.

a. Dependant on personnel expertise may need to outsource.

b. Time consuming.

c. Can be expensive.

d. Only relevant at that particular point in time.

e. No transferable metric provided hard to communicate importance to other departments.

f. Not indicative of importance of the asset in meeting the organisational objectives.

The last weakness is very significant as we are told that "at the shop-floor level, the maintenance processes which mainly focus on repairing and breakdown services, are sometimes started in a non co-ordinated way, even in contradiction to business objectives, and without a real estimate of different effectiveness factors other than the availability impact" [1].

In addition, providing a transferable metric is more important now than ever before, as Iung states "the objective today is to industrially implement and evaluate a collaborative maintenance with the possibility to demonstrate in site its added value" [9].

Traditionally, methods of criticality analysis have been used to determine the maintenance strategy to adopt for an asset. Once this strategy has been commissioned it is unlikely that the results of the analysis will be used to assist in the prioritisation of maintenance activities on a day-to-day basis. An inherent problem of criticality assessments is that they are static procedures that don't update as the operating environment alters. The criticality of an asset will inevitably vary with time as it depends on a multitude of factors.

In an ongoing case study at a food processing facility it has been identified that the criticality of certain sections of the production line varies greatly depending on the production schedule. This is due to different products requiring different equipment sections for their production. Therefore when a section of equipment is not required, it is not critical. This is illustrated in Figure 1.

When there are two or more products being produced at the same time or there are two or more lines to maintain, criticality will also vary. For example, if there are two identical machines on two identical lines producing two similar products, it may be fair to assume that both machines have the same criticality. However, if one machine is producing a more profitable product then it is more critical than the other as the consequences to the organisation are greater in the event of a failure (assuming all other variables are equal).

Current methods have no facility to deal with this and over time the assigned criticality will become inaccurate.

To fully utilise the time, effort and expense required to carryout a criticality analysis, the analysis needs to be ongoing and used not just to determine strategies but to assist in prioritising activities on a day-to-day basis. 


\subsection{Review of models which integrate condition and criticality}

There is a great deal of literature which concentrates on modelling for fault diagnosis and location, but there is less which deals with decision making in maintenance management.

Jardine's method uses a Markov chain to represent the behaviour of a physical system, and combines a number of condition indicators, coupled with failure cost data and life expectancy. The factors are combined in the proportional hazard model. The future evolution of a Markov system is only dependent upon the present condition, unlike a regression method which predicts a dependent variable based upon the history of several independent variables. The method is marketed as the EXAKT ${ }^{\mathrm{TM}}$ system, in which the risk factors are combined with the failure history and costs of both planned maintenance and unpredicted failures, to obtain the optimal replacement interval for a group of machines. The technique does not deal with the prioritisation of a range of potential actions. [10]

Sherwin described the application of Weibull analysis to extensive failure data to effect decision-making on maintenance in the process industries. The technique is appropriate for determination of the failure regime, and hence to modify maintenance policy. It is however somewhat reliant on having sufficient failure data to analyse, and does not attempt to prioritise individual events. [11]

Al-Najjar assessed maintenance strategies using a fuzzy multiple criteria decision making (MCDM) evaluation methodology, and showed how the most informative or efficient maintenance approach would lead to less planned replacements, reduced failures higher utilization of component life. The relationship with business objectives was discussed, but the emphasis was on strategy rather than individual events. [12]
Wang applied a stochastic recursive control model to condition based maintenance. Actions to be taken, and optimal condition monitoring intervals, were considered as different decisions. A stochastic recursive filtering model predicted residual life, and then a decision model recommended actions. [13]

Al-Najjar \& Wang noted the paucity of the literature in the field and presented a unified conceptual approach with the problems in the paper manufacturing sector in mind. The model integrates condition information, deterministic models used in condition monitoring, and probabilistic models used in operational research. The working of the model is extensively discussed in the context of a rolling element bearing. The model does not consider the problem of multiple alarm events. [14]

Al-Najjar proposed an all-encompassing approach called Total Quality Maintenance, which combines the areas of production and maintenance to maximise competitiveness, and central to which is a common database. The concept recognised the problems that we have tried to tackle in this work, and hence there is certainly scope in the concept for ranking of potential CBM failures, but it is not explicitly described. It was acknowledged that plenty of real data would be required for testing. [15]

Hence, the majority of work reported in the literature has concentrated on residual life, replacement decision, and strategic choice, and the traditional statistical approach has moved towards a more philosophical and pragmatic one with hybrid mathematical methods, but practical aspects of the solutions remain a challenge because of lack of data from real integrated systems. 


\section{Data Fusion architecture}

\subsection{Integrating Information Systems}

It has been estimated that the penetration of condition monitoring (CM) is only 10-20 per cent of its potential. This represents a loss of up to $£ 1.6$ billion in the UK alone [16]. A limiting factor is the existing level of systems integration. Starr and Ball [4] suggest that this can be addressed by the holistic approach and the adoption of new technology, including:

a. open global electronic information systems;

b. adaptive shared communications media;

c. smart sensors;

d. adaptive flexible decision-making algorithms.

Integration theory combines the application of holistics and global performance criteria. The concept of asset management optimises labour, tools, equipment, materials, and information by integrating financial, human resources, and purchasing functions, as well as production, materials requirements planning, and enterprise resources planning systems [17]. The integration of computerised maintenance management systems (CMMS) with enterprise asset management (EAM) systems can simplify this process.

Ultimately, all decisions should be made inline with the business objectives and drive the business forward. This requires a comprehensive view of the internal systems of the organisation.

\subsection{Isolated Islands of Data}

Decision makers within organisations regularly face the same problem; how do they get the information they need to make the most effective decision? To identify what information a maintenance manager will require when making decisions on a daily basis we must first consider his overall objective. A common definition of the objective of a maintenance department is to "achieve the agreed plant operating pattern, product output and quality, within the accepted plant condition and safety standards, and at minimum resource cost"[18]. So with this objective in mind; what information will he require? In order to make sound judgements a maintenance manager will typically need to know to the following:

- production schedule;

- equipment requirements;

- equipment condition;

- required quality level;

- required safety \& environment legislation;

- available resources;

- priority of tasks.

This information is available from the following sources [19]:

- production schedules;

- condition monitoring systems;

- maintenance management systems;

- financial records;

- health \& safety regulations.

The realistic level of access to data from these sources today is, at best, a search across servers to find the correct spreadsheet or database, and at worst, it involves visiting each of the appropriate people to retrieve paper copies of the information. This can be a very time consuming task. When decisions must be made quickly, management may be forced to go on 'gut-feeling' This seems ridiculous at a time when the media would have us believe we are living in the "information age". The reality of the matter is somewhat different. Paper reports exist and are not all read. This casts doubt on the effective deployment of resources. 


\subsection{Centralising Data}

It has been suggested that the way forward for the storage of data required by maintenance managers is to create a centralised database to house the relevant data from each information system [15,20]. This sounds a suitable solution but is laden with difficulties. Many of the information systems that can be found in organisations have been acquired by departments over periods of time and normally without consultation with other departments. Many of the systems are not compatible with each other and that data is stored in formats that prevents it from being brought together easily in a centralised database.

Large databases can have many drawbacks; they can become unwieldy and require complex hardware and software to operate effectively. Setup costs can be very high and due to the complexities of the system, operational and maintenance costs can escalate to many times the original outlay. In addition, if the system suffers a failure then many subsystems are affected instead of one. Making backups of large centralised databases can be both time consuming and expensive.

\subsection{Remote Data Access}

The physical location of a database is no longer important. Indeed, private networks and the internet routinely service fast, remote data requests. Furthermore, it is not necessary for all data entities to be in the same electronic table or even the same relational database. Particularly where several systems are managed separately, largely for separate purposes, it would be unwise to combine them. The key advance is top-level information gained by dynamic linking. Such information is current and "real-time" - decisions can be made with current, not historical, data.
An example of linked databases is the passing of job information and billing data from a facilities management system to a maintenance management system (and vice versa) at a London Bank [21].

The technical task is not difficult - it is simply a standardised request for text or numbers. The problem lies in the formulation of the architecture of the integration, and hence knowing what to ask for, and where.

A remote access method, combined with an appropriate dynamic algorithm, can bring many of the benefits of a centralised database but eliminate many of the pitfalls. It is preferred that data is requested in advance from each proprietary information system to an intermediate database, which can be queried by the algorithm - this is more robust. Data can be passed each time there is a change in any of the measured parameters or on the request of the algorithm. As this data is only required at the time of the calculation, no backups are required and if the system fails then the original systems are still in place.

Naturally it is possible to avoid the use of an intermediate database, but the data transfer problem starts to resemble a serial reliability problem - there are many potential sources of failure. Figure 2 illustrates the simplified data retrieval system.

\subsection{Data fusion as an integration model}

The data and information sources must be combined automatically, quickly and iteratively. Maintenance management is not unique in searching for methods to automate decision-making: the problem occurs in medicine, non-destructive testing, robotics, condition monitoring and in military applications, where extensive theoretical work has been laid down. A model for data fusion was standardised by the US military 
Joint Directors of Laboratories (JDL) and is illustrated in figure 3[22].

Note that other models exist, but they tend to be specific to an application such as robotics or machine vision, so we have not explored them further here. It is useful to consider briefly the "engineering guidelines" for applications, which are outlined below: identification, estimation and validation [23].

The model is useful because it considers the combination of data and information for decision processes at every step from measured data to performance appraisal. It has been widely applied to condition monitoring processes, but is equally applicable to information for maintenance management.

At this level the true capability of the model becomes apparent - many applications are concerned with fusion of measured parameters, or model-based methodologies, but still only give a numerical estimate of health condition. Here we aim to combine the health condition with the wider issues of cost and risk, because decisions made from this information are frequent and crucial.

Note that the model does not prescribe a set algorithm for the fusion process. The model aims to get the best combination of data and information - it is not dogmatic. Depending on the data and information types, the fusion might involve a wide range of mathematical approaches, but it is likely that the right technique will be very simple once the preprocessing is complete.

\subsubsection{Identification}

This stage makes inferences about the system.

- Identify the information to be gained by using data fusion.

- Understand the phenomenon under study.

- Understand the data sources including collection and measuring techniques.
- Pre-process the data: synchronisation, dimensional reduction, concentration, repeatability, redundancy.

- Identify uncertainty and minimise it.

- Identify the level at which fusion must take place - low level for sensors, high level for information/decisions.

\subsubsection{Estimation}

This is performed at the appropriate level of inference. Two taxonomies are popular to select the data fusion algorithm in order to deal with a range of data sources, e.g. time series and images:

- a four level hierarchy consisting of signal, pixel, feature, and symbol levels; - a classical JDL model of data fusion.

After the core hierarchical architecture has been selected according to the type of data and application, algorithm selection is made at each level.

\subsubsection{Validation}

The processed data and the fused information is confirmed at the validation stage, where performance assessment and a benchmark procedure are implemented:

- performance assessment, measuring the uncertainty content;

- benchmark procedure to improve the output results;

- feedback and fine tuning.

\section{Cost-Based Criticality}

Cost-Based Criticality (CBC) is a new methodology being developed to solve many of the issues with current criticality assessment methods. CBC is intended to prioritise maintenance activities when large numbers of condition-based alarms are raised.

Similar to other criticality assessments, CBC uses the probability of occurrence and resulting consequences of an asset failure to 
rank assets. The differentiating factor is that $\mathrm{CBC}$ will use cost as the consequence metric so that the criticality can be illustrated to interested external parties more easily. It will also encompass more variables into the consequence section of the analysis and integrate the requirements of the production department because assets which are critical today may not be critical for subsequent orders. Figure 4 illustrates the Cost-Based Criticality process.

To balance the benefits of each activity with the cost of performing it, 'Cost-Benefit Analysis' (CBA) will be used. CBA is a well established method where a list of burdens and benefits is made and monetary values assigned. Then the net cost is calculated by subtracting the cost of the burdens from the cost rewards of the benefits [24].

Evidently there are some benefits or burdens, such as safety or quality, which cannot be easily expressed directly in terms of monetary values. However, these factors can have values estimated which represent the minimum amount of money that the organisation would accept in their place. This value should be determined by examining tradeoffs between money and the intangible factor [25].

An example of this trade-off process is shown by the UK Department of Transport, describing 'Road Accidents Great Britain 1997'. It states that "It contained an article describing the results of recent research on the value of prevention of a road accident fatality. The research showed that a figure in the range $£ 750,000$ to $£ 1,250,000$ in 1997 prices could be regarded as being broadly acceptable" [26]. This is the most difficult element of CBA and is only possible when all participants agree with the prices used.

CBC will operate by drawing existing data from isolated islands of data into a criticality algorithm so that a CBC value can be determined for each asset. This operation will be performed each time there is a change in the organisation's environment such as an increase in the price of raw materials, change is asset health or the production of a different product. The $\mathrm{CBC}$ values will then be used to rank maintenance activities in order of priority at that point in time.

\subsection{Fusion algorithms}

The fusion "engine" sits within the architecture for collecting and reporting the data and information, and is implemented by an algorithm for combining those entities. There is a wide range of fusion algorithms, suitable for different data types and problem architectures [27]. For example:

- where clear rules or heuristics are available, knowledge based systems or fuzzy logic are appropriate;

- a robust model is worth using if it exists;

- if no model or rules exist, but there is a large quantity of data, then numerical techniques like neural networks may be trained for pattern recognition.

In practice, many engineers dislike the latter example because they prefer the auditable decision-making of the former methods. Any method used must generate trust in its users, or it will be shelved.

In this instance we have kept the algorithm very simple, as shown below. Research in progress will test more sophisticated algorithms, but this will not be further explored here.

\subsection{Probability of Asset Failure}

In order to determine the probability of an asset failure, an in-depth analysis of the historical reliability data must be carried out to determine the reliability and availability of each asset. If sufficient data is unavailable then appropriate data can be sourced from 
reliability data suppliers. This will be suitably accurate. However, if the assets being assessed are bespoke products with little or no similarity to anything else on the market, approximations may have to be used.

\subsection{Consequences of Asset Failure}

Consequences of failures will be identified using a set of criteria. Each criterion will have a monetary value assigned to represent the potential cost to the organisation. In addition, consideration will be given to other elements which affect the total downtime cost such as set-up times, spare part lead times and time taken to find someone to repair the fault.

The first decision to be made for a criticality analysis is to decide those criteria on which to base the analysis. The method under development aims to use criteria, selected from a core list, which may be omitted or tailored to meet the needs of the individual organisation. The core criteria are:

\section{- Production Loss}

Production loss will be calculated by determining the reduction in production rate for the asset due to a failure and multiplying this by the value that would have been added in the process. However, the value added to a product by an asset will change in many organisations depending on what product is being produced at that particular point in time. Consequently the system must have access to the production schedule to determine an accurate figure.

\section{- Capital Loss}

Capital loss is the sum cost of labour, spare parts and any secondary damage that would be caused to other assets in the event of a failure.

\section{- Quality Loss}

Quality loss is the estimated cost of a reduction in quality, reworking or scrap due to an asset not meeting specified tolerance levels or any other quality related issues.
- Safety \& Environment

Safety and environment costs are any fines or compensation claims that have been incurred as a direct result of an asset failure.

\section{- Customer Satisfaction}

Customer satisfaction is the cost of lost orders or fines due to late orders as a result of asset failures.

These criteria are not exhaustive or dogmatic, and could be adapted to suit different applications with differing sensitivities.

\subsection{CBC Value}

The CBC value is a product of a probability and a consequence. Therefore, the output from the CBC algorithm will be a probability of incurring a cost if a maintenance activity is not carried out.

$\mathrm{CBC}$ is calculated as follows:

$$
\mathrm{CBC}=\Sigma(\mathrm{P}, \mathrm{C}, \mathrm{Q}, \mathrm{SE}, \mathrm{CS}) \cdot \mathrm{P}_{\mathrm{f}} \quad(\text { eq. 1) }
$$

Where the estimates of potential cost impact are:

$$
\begin{aligned}
& \mathrm{P} \text { - production loss; } \\
& \mathrm{C} \text { - capital equipment; } \\
& \mathrm{Q} \text { - quality; } \\
& \mathrm{SE} \text { - safety and environment; } \\
& \mathrm{CS} \text { - customer satisfaction; }
\end{aligned}
$$

and $P_{f}$ is the probability of failure. Note that the $\mathrm{CBC}$ calculation is not invoked unless the condition monitoring alarm is set.

As an example, the following numbers for an incident are introduced from a food plant:

$$
\begin{aligned}
& P=1200(f) \\
& C=200 \\
& Q=100 \\
& S E=0 \\
& C S=200 \\
& P_{f}=0.05
\end{aligned}
$$

Hence $\mathrm{CBC}=1700 \times 0.05=£ 85$. 


\subsection{Examples}

\subsubsection{Ranking}

Table 2 illustrates a summary table of top ranking faults with some simulated data. On the right hand side of the table, the final column, "CBC value" gives the potential impact; its unit is $£$, but the measure is intended to be relative rather than absolute. The CBC value implies a combination of risk and cost, and hence the highest should be actioned first. This number needs no further processing by the human decisionmaker: it is a scalar. The list is "live", such that it is revised at a practical frequency, e.g. daily.

When the table is ranked, the human decision-maker can select all those tasks for which he has the resources to perform. Note that the others will remain in alarm, and might fail, but we have chosen more critical risks first. Low risk alarms remain on the list for further consideration at the next ranking. Usually this will not lead to catastrophic failure, because the condition monitoring will give plenty of warning. If the alarm does not reach the top of the list before failure, it remains relatively low risk.

\subsubsection{Derivation}

Table 3 illustrates how the $\mathrm{CBC}$ values are calculated using the core criteria. On the left of the table, each entry on the list is identified by its day, location and current product. The consequence criteria are extracted from the table simply for clarity of layout; they are part of the same database table.

\subsubsection{Differential CBC values}

Table 3 displays consequential costs for two similar machines on two different lines producing different products. The consequential costs of failures are based on one particular failure mode that is common to both machines and it is assumed that the probability of occurrence is the same in both machines. The table illustrates how the CBC value changes as the machines switch production from one product to another. Initially machine 001023 FAM (labelled A) is more critical than machine 001024 GME (labelled B). As the latter machine changes production to product "STK $\mathrm{C} / \mathrm{C}$ "*, it becomes the more critical (labelled $\mathrm{C}$ ). In effect, for the first three days of production 0010023 FAM would receive attention first if both machines required attention. For the latter three days 001024 GME would have priority.

*Note: the codes are not explained further because the work is commercially sensitive.

\subsubsection{Schedule change}

Table 4 summarises the differences introduced by a change in operating schedule on the same machines. As indicated in figure 1 different products, or even differing quality of similar products, can use different modular production machinery and give different risks on the same machines. The table indicates a simulated range of changes caused by increases and decreases in the failure probability and the consequence cost. The importance is not in the exact numbers but in the range of potential change from one production schedule to the next.

To underline this effect, Table 5 tracks an alarm under different schedule conditions from rank order 34 to rank order 55 as its $\mathrm{CBC}$ value is more than halved.

\section{Discussion}

It is important to examine the results of this approach and its added value related to conventional approaches. It is difficult to quantify the benefit in the initial testing, because it would need years of testing in the field. We know that the human decision- 
maker can only attempt an approximation to an optimal ranking. It is not likely that the human decision-maker will respond well to common complexities, such as combinatorial problems of multiple potential jobs, or of rearrangement of modular plant, which leads to different criticality ratings (most criticality analysis remains paperbased). We have three options for performance assessment.

i) Wait several years, consistently running CBC alongside a human decision-maker; perhaps ideal, but this is not likely to be successful, because of staff changes, and the typical industrial demand for a quick result.

ii) Simulate scenarios within the data which replicate likely change of ranking order, which we believe would not usually be included automatically, and compare the influence of the top jobs selected. It is not possible to say whether the human decisionmaker might occasionally also include these changes, but our survey work suggests not. This option is explored in the results.

iii) Compare different algorithms for $\mathrm{CBC}$ : the current algorithm is deliberately very simple. More sophisticated algorithms can be used to create the ranking, and then the top jobs can be compared by simulation as in ii) to evaluate any improvement in performance. This is work in progress.

Ideally one would predict a cost benefit or improved availability but we cannot do this in the short term. This is, however, a typical problem in this area of research.

At present the method of combining the probability of failure with the consequential cost is simple. However, more complex methods are currently being tested as part of a further case study at a food processing facility.

\section{Conclusions and further work}

- The increase in use of condition monitoring techniques combined with simplified methods of setting condition- based maintenance alarms has led to maintenance personnel having to deal with large numbers of alarms.

- In an ongoing case study at a food processing facility it has been identified that the criticality of certain sections of the production line varies greatly depending on the variables such as the production schedule.

- It has been identified that a criticality analysis needs to be continuous and determine the criticality of assets on a daily basis so that alarms from the CMMS can be ranked in order of priority.

- Current criticality analysis techniques are unable to deal with this problem as they are static procedures used primarily to identify initial maintenance strategies.

- Cost-Based Criticality has been introduced as a method to prioritise maintenance activities based on the ability of the asset in question to affect the profitability of the organisation.

- The process utilises an algorithm which eliminates the need for a cumbersome centralised database and simplifies implementation.

- Although at present in its infancy and using only simplistic methods to combine prioritisation factors, initial testing has indicated promising results. A good performance metric is required for scenario analysis.

- The system architecture requires further work and will be reported in more detail in future publications.

- Further optimisation of the core fusion process is underway. A number of artificial intelligence methods are suitable, but a particular interest is the ability to deal with missing data items. 


\section{Acknowledgements}

The authors would like to thank PAS Grantham and its staff, in particular John Bowman, for their cooperation in the ongoing case study, and gratefully acknowledge the support of the Engineering and Physical Science Research Council (EPSRC) and the former staff of Wolfson Maintenance. 


\section{References}

[1] Mulcahy, R. (1999). The CMMS technology revolution - Why "Best-of Breed" will still be best. International Journal of Maintenance and Asset Management, 14(1), 11-14.

[2] Bever, K. (2000). Enterprise Systems Integration: Opportunities \& Obstacles Developing Plant Asset Management Systems. National Manufacturing Week, Chicago 2000.

[3] Baldwin, R.C. (2004) Enabling an E-Maintenance Infrastructure. www.mt-online.com, last accessed October 2005

[4] Starr, A and Ball, A. (1999). Systems Integration in Maintenance Engineering. Proceedings of the Institute of Mechanical Engineers Part E - Journal of Process Mechanical Engineering (Special Edition), v214 pp79-95

[5] http://www.devicesworld.net/emaintenance.htm, last accessed October 2005

[6] Willetts, R, Starr, A.G, Doyle, A and Barnes, J. (2005). Generating Adaptive Alarms For Condition Monitoring Data. International Journal of COMADEM, ISSN 1363-7681, v8 no 3 pp26-36

[7] Labib, A.W, O’Connor, R.F and Williams, G.B. (1998). An Effective Maintenance System using the Analytic Hierarchy Process. Integrated Manufacturing Systems, MCB University Press.

[8] Standardisation Organisations Norway. (2001). NORSOK Standard.

[9] Iung, B. (2003). From remote maintenance to MAS-based e-maintenance of an industrial process. Journal of Intelligent Manufacturing, v14, n1 pp59-82.

[10] Jardine, A.K.S.; Makis, V.; Banjevic, D.; Braticevic, D.; Ennis, M., (1998), Decision optimization model for condition-based maintenance, Journal of Quality in Maintenance Engineering, v 4, n 2, p 115-121, ISSN: 1355-2511

[11] Sherwin, D. J., Lees, F. P., (1980), Investigation of the application of failure data analysis to decision-making in maintenance of process plants - 1. General and theoretical background, Proceedings of the Institution of Mechanical Engineers, v194, p 301-307, ISSN: 00203483

[12] Al-Najjar, B, Alsyouf, I, (2003), Selecting the most efficient maintenance approach using fuzzy multiple criteria decision making, International Journal of Production Economics, v 84, n 1, p 85-100, ISSN: 0925-5273

[13] Wang W, (2002), A stochastic control model for on line condition based maintenance decision support, Proc. 6th World Multiconference on Systemics, Cybernetics and Informatics. pt. 6, p 370-4 vol.6 ISBN: 9800781501 
[14] Al-Najjar, B, Wang, W, (2001), A conceptual model for fault detection and decision making for rolling element bearings in paper mills, Journal of Quality in Maintenance Engineering, ISSN: 1355-2511, v7, Issue: 3 Page: 192 - 206

[15] Al-Najjar, B, (1996), TQMain; a common database for total quality maintenance, an approach for continuous reduction in costs of quality products, Journal of Quality in Maintenance Engineering, Vol. 2 No.3, pp.2-20.

[16] Kennedy, I. (1998). Holistic machine condition monitoring. In Proceedings of the Seminar on Advances in Maintenance Engineering, University of Manchester, 1998.

[17] Dilger KA. (1997). Asset management, maintenance redefined. Manufacturing Systems, Vol.15, No.7, pp.122-124, 126-128, ISSN 0748-948X

[18] Kelly, A. (1997). Maintenance Strategy - Business Centred Maintenance. ButterworthHeinemann

[19] Fitchett, D. (2001). TDC - Downtime Data Sources. Facilities America Conference 2001.

[20] Al-Najjar, B, Alsyouf, I. (2004). Enhancing a company's profitability and competitiveness using integrated vibration-based maintenance: A case study. European Journal of Operational Research, Volume 157, Issue 3, pp 643-657.

[21] Starr, A, Wynne, R, Kennedy, I. (1993). Condition monitoring of building services - a case study in a high technology building. Proceedings of COMADEM 93 (Condition Monitoring and Diagnostic Engineering Management congress), Bristol, July 1993 pp473478.

[22] Llinas, J, Hall, D. L. (1998). An introduction to multi-sensor data fusion. Proc. IEEE International Symposium on Circuits and Systems 6: 537-540.

[23] Esteban J, Starr A, Willetts R, Hannah P, Bryanston-Cross P, (2005), A review of data fusion models and architectures: towards engineering guidelines, Neural Computing \& Applications, Springer-Verlag London Ltd, ISSN: 0941-0643 (Paper) 1433-3058 (Online), Volume 14, Number 4, pp273 - 281

[24] Bedford, T. \& Cooke, R. (2001). Probabilistic Risk Analysis: Foundations And Methods. Cambridge University Press.

[25] Watkins, T. (2004). Introduction to Cost Benefit Analysis. San Jose State University Economics Department.

[26] Department of Transport. (2002). Highway Economics Note No.1 2002. www.dft.gov.uk, last accessed October 2005 
[27] Varshney P.K. (1996). Distributed Detection and Data Fusion. Springer-Verlag New York Inc. ISBN: 0387947124 
Figures:

Figure 1. Varying Criticality in a Production Line

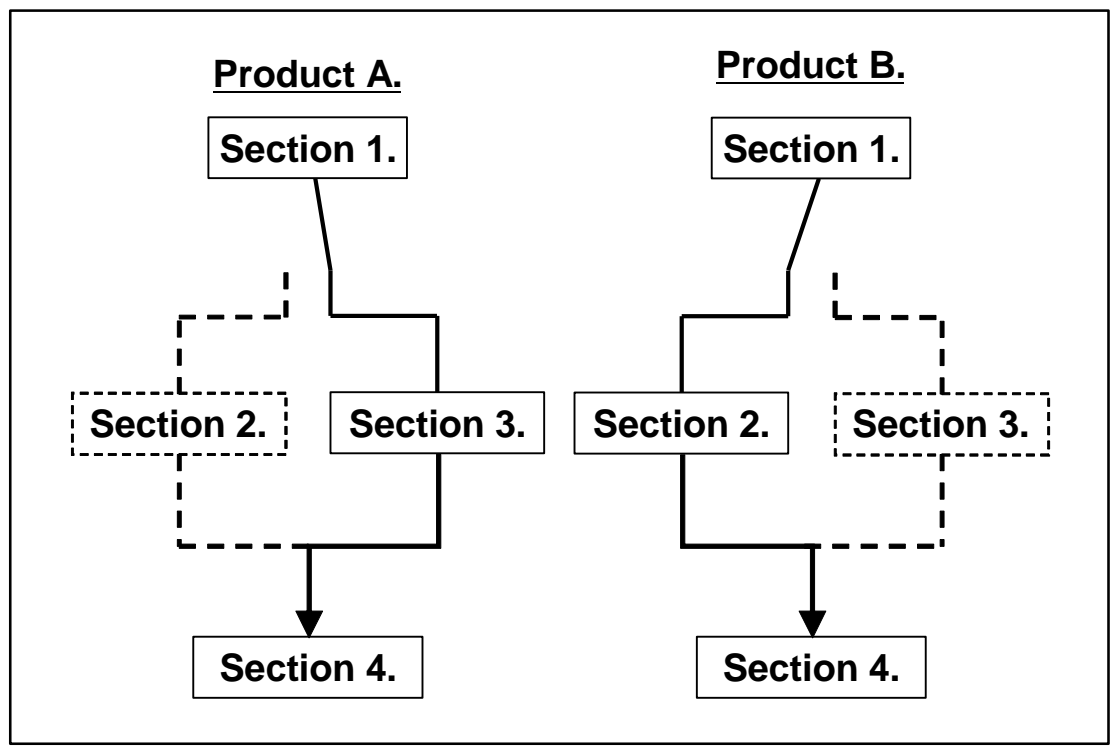

Page 18 of 26 
Figure 2. CBC Data Retrieval Architecture

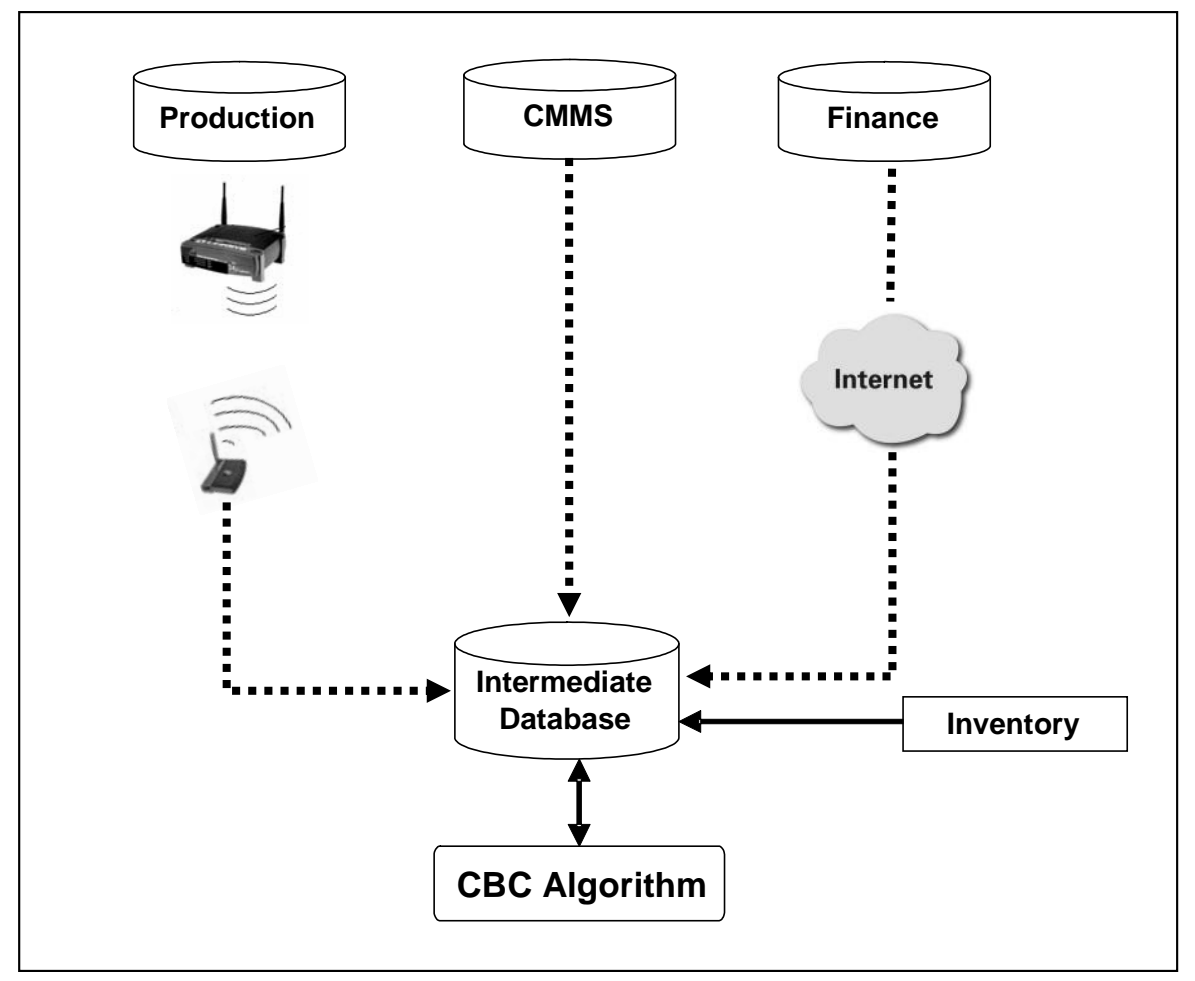

Page 19 of 26 


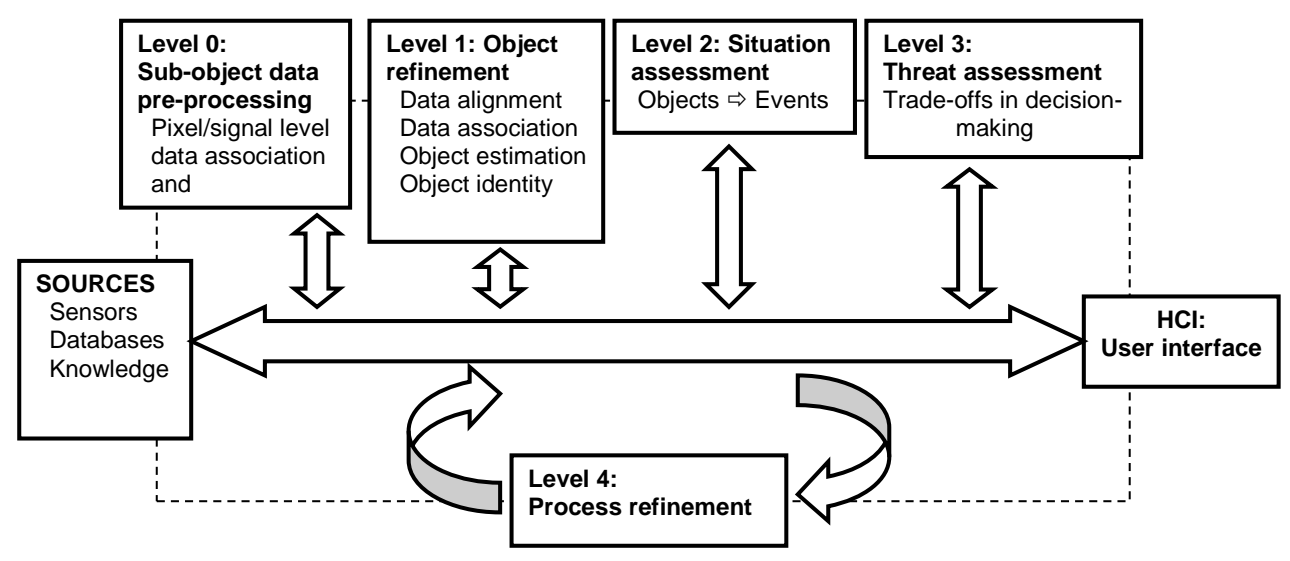

Figure 3: The JDL data fusion framework [27] 
Figure 4. The CBC Process

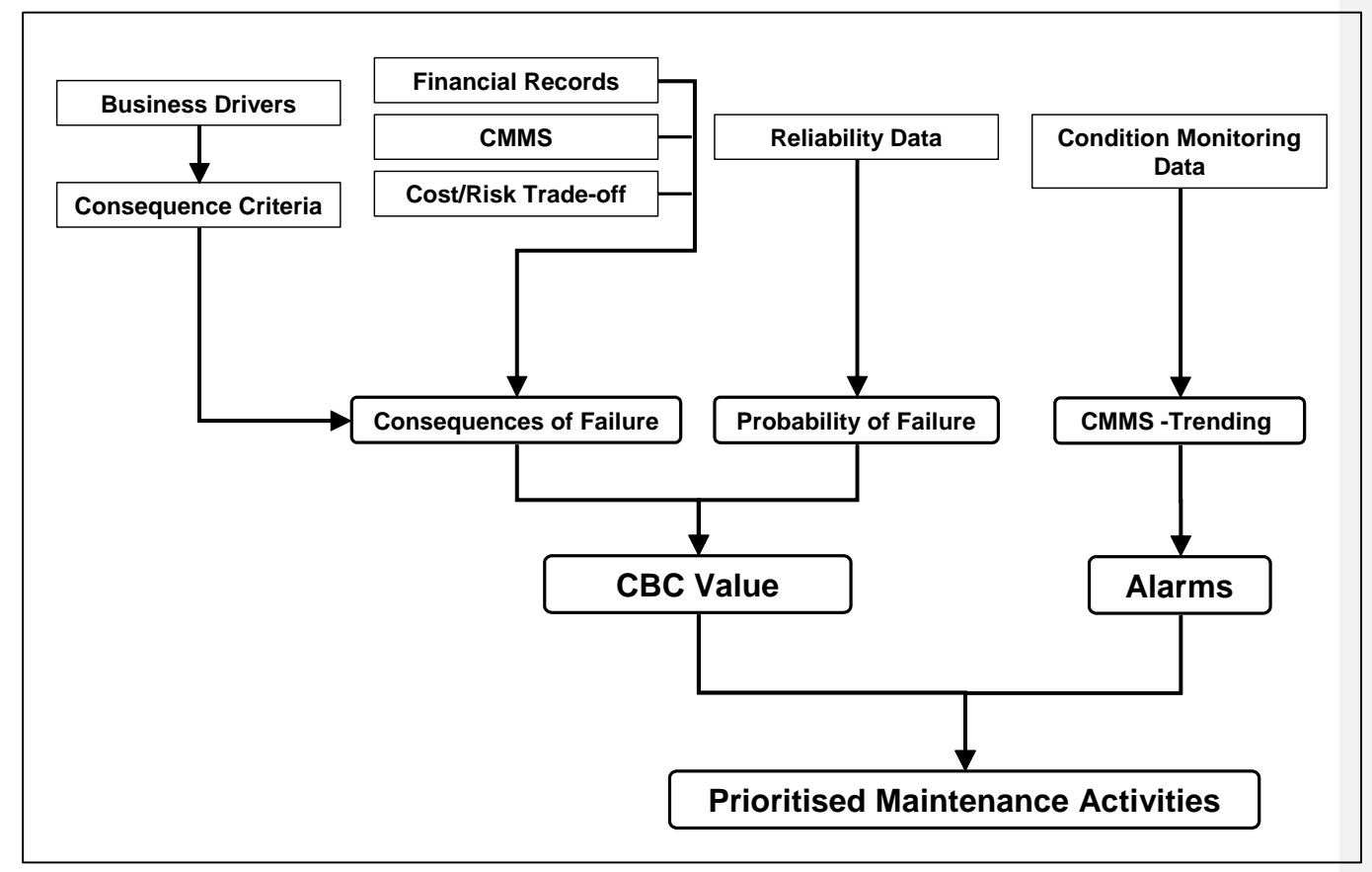

Page 21 of 26 
Tables:

Table 1: NORSOK Criticality Classification Table [13]

\begin{tabular}{|l|l|l|l|}
\hline Class & Health, Safety \& Environment & Production & $\begin{array}{l}\text { Cost (exclusive } \\
\text { production loss) }\end{array}$ \\
\hline High & $\begin{array}{l}\text { Potential for serious personal injuries. } \\
\text { Render safety critical systems inoperable. } \\
\text { Potential for fire in classified areas. } \\
\text { Potential for large pollution. }\end{array}$ & $\begin{array}{l}\text { Stop in production/ } \\
\text { significant reduced rate of } \\
\text { production exceeding X } \\
\text { (specify duration) within a } \\
\text { defined time period. }\end{array}$ & $\begin{array}{l}\text { Substantial cost }- \\
\text { exceeding Y NOK } \\
\text { (specify cost limit). }\end{array}$ \\
\hline Medium & $\begin{array}{l}\text { Potential for injuries requiring medical } \\
\text { treatment. } \\
\text { Limited effect on safety systems. } \\
\text { No potential for fire in classified area. } \\
\text { Potential for moderate pollution. }\end{array}$ & $\begin{array}{l}\text { Brief stop in } \\
\text { production/reduced rate } \\
\text { lasting less than X hours } \\
\text { (specify duration) within a } \\
\text { defined period of time. }\end{array}$ & $\begin{array}{l}\text { Yoderate cost between Z- } \\
\text { limits). }\end{array}$ \\
\hline Low & $\begin{array}{l}\text { No potential for injuries. } \\
\text { No potential for fire or effect on safety } \\
\text { systems. } \\
\text { No potential for pollution. }\end{array}$ & $\begin{array}{l}\text { No effect on production } \\
\text { within a defined period of } \\
\text { time. }\end{array}$ & $\begin{array}{l}\text { Insignificant cost less than } \\
\text { Z NOK (specify cost } \\
\text { limit). }\end{array}$ \\
\hline
\end{tabular}


Table 2: Top ranking CBC value summary

\begin{tabular}{|l|l|l|l|l|}
\hline Rank & Asset & $\begin{array}{l}\text { Probability of } \\
\text { Failure }\end{array}$ & $\begin{array}{l}\text { Consequence of } \\
\text { Failure }\end{array}$ & CBC Value \\
\hline \hline 1 & 001609 VIB & 0.53 & $£ 56,361$ & $£ 29,871$ \\
\hline 2 & $001601 \mathrm{FRE}$ & 0.96 & $£ 25,989$ & $£ 24,949$ \\
\hline 3 & $001359 \mathrm{VIB}$ & 0.46 & $£ 45,017$ & $£ 20,708$ \\
\hline 4 & $001501 \mathrm{FRY}$ & 0.96 & $£ 19,904$ & $£ 19,108$ \\
\hline 5 & $001334 \mathrm{VIB}$ & 0.61 & $£ 28,257$ & $£ 17,236$ \\
\hline 6 & $001412 \mathrm{PP}$ & 0.51 & $£ 33,322$ & $£ 16,994$ \\
\hline 7 & 001416 DRY & 0.78 & $£ 21,318$ & $£ 16,628$ \\
\hline 8 & 001353 ADR & 0.92 & $£ 15,468$ & $£ 14,231$ \\
\hline
\end{tabular}


Table 3: Calculating CBC Values

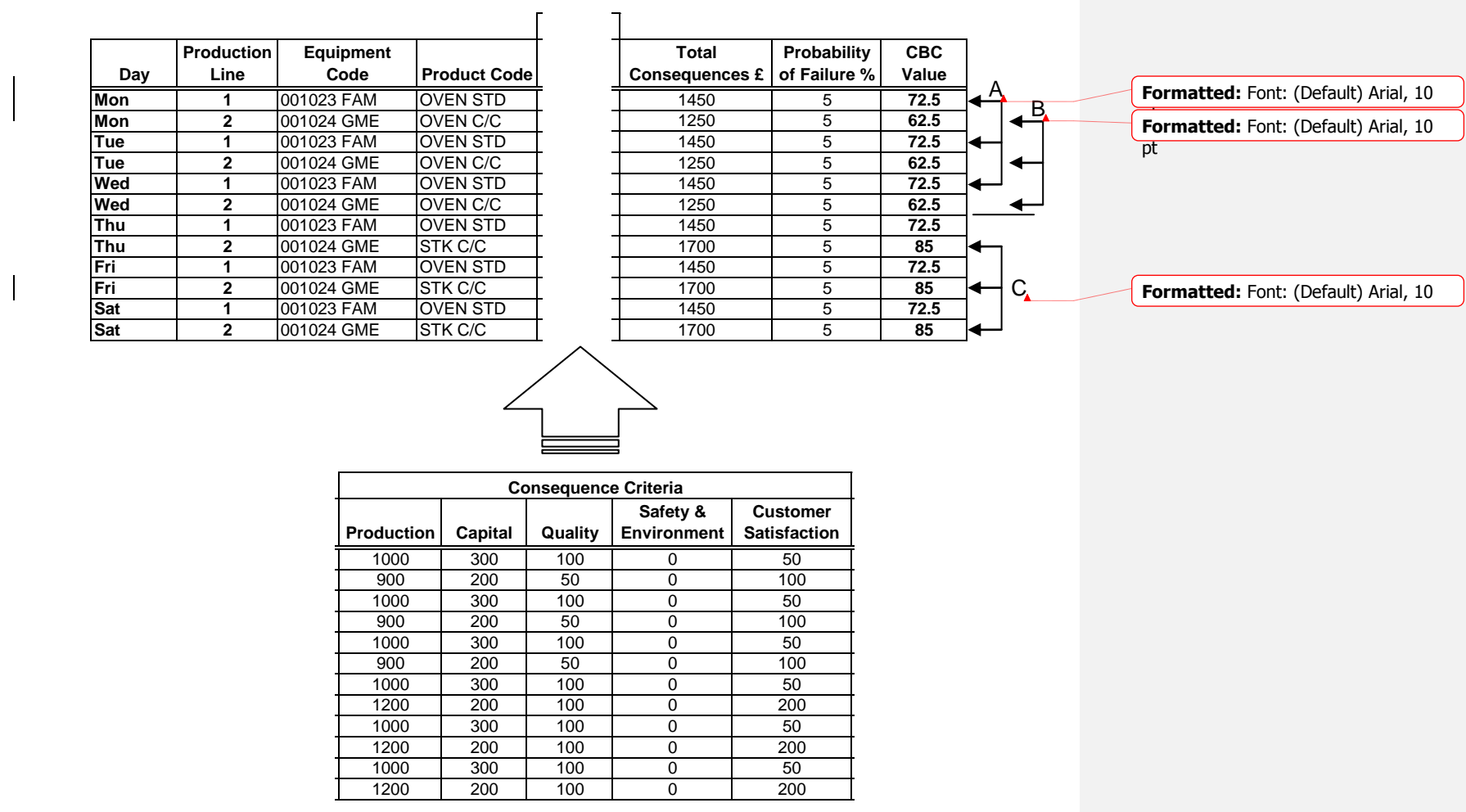

Page 24 of 26 
Table 4: Changing CBC values with schedule

\begin{tabular}{|l|c|c|c|c|c|c|c|}
\cline { 2 - 7 } \multicolumn{1}{c|}{} & \multicolumn{2}{c|}{$\begin{array}{c}\text { Probability of } \\
\text { Failure }\end{array}$} & \multicolumn{2}{c|}{$\begin{array}{c}\text { Potential } \\
\text { Consequence }\end{array}$} & \multicolumn{2}{c|}{ CBC Value } & \multicolumn{1}{c|}{} \\
\hline Asset & $\begin{array}{c}\text { Schedule } \\
\text { A }\end{array}$ & $\begin{array}{c}\text { Cchedule } \\
\text { B }\end{array}$ & $\begin{array}{c}\text { Schedule } \\
\text { A }\end{array}$ & $\begin{array}{c}\text { Schedule } \\
\text { B }\end{array}$ & $\begin{array}{c}\text { Schedule } \\
\text { A }\end{array}$ & $\begin{array}{c}\text { Schedule } \\
\text { B }\end{array}$ & $\%$ Variation \\
\hline 001205 PP & 0.12 & 0.15 & $£ 12,392$ & $£ 12,134$ & $£ 1,487$ & $£ 1,820$ & $\mathbf{2 2 . 4}$ \\
\hline 001211 CUT & 0.19 & 0.08 & $£ 8,170$ & $£ 8,019$ & $£ 1,552$ & $£ 641$ & -58.7 \\
\hline 001208 CUT & 0.31 & 0.13 & $£ 9,866$ & $£ 9,674$ & $£ 3,058$ & $£ 1,257$ & -58.9 \\
\hline 001209 CUT & 0.32 & 0.13 & $£ 8,558$ & $£ 8,397$ & $£ 2,738$ & $£ 1,091$ & -60.1 \\
\hline 001207 VIB & 0.08 & 0.03 & $£ 6,862$ & $£ 6,741$ & $£ 549$ & $£ 202$ & -63.2 \\
\hline 001206 VIB & 0.03 & 0.01 & $£ 6,155$ & $£ 6,048$ & $£ 184$ & $£ 60$ & -67.3 \\
\hline
\end{tabular}


Table 5: Effect on an individual CBC values with schedule

\begin{tabular}{|c|c|c|c|c|c|}
\hline \multicolumn{3}{|c|}{ Production Schedule A } & & & \\
\hline Priority & Asset & CBC Value & \multirow{2}{*}{\multicolumn{3}{|c|}{ Production Schedule B }} \\
\hline 32 & 001328 RNR & $£ 4,256$ & & & \\
\hline 33 & \multirow{2}{*}{$\begin{array}{c}001101 \mathrm{CON} \\
\mathbf{0 0 1 2 1 4} \mathbf{P P}\end{array}$} & \multirow{2}{*}{$\begin{array}{l}£ 4,169 \\
£ 4,078\end{array}$} & \multirow{2}{*}{$\frac{\text { Priority }}{52}$} & \multirow{2}{*}{ Asset } & CBC Value \\
\hline 34 & & & & & $£ 1,782$ \\
\hline 35 & $001424 \mathrm{CON}$ & $£ 3,891$ & 53 & 001378 PP & $£ 1,753$ \\
\hline 36 & $001519 \mathrm{VIB}$ & $£ 3,856$ & 54 & $001901 \mathrm{PP}$ & $£ 1,575$ \\
\hline & & & 55 & 001214 PP & $£ 1,496$ \\
\hline & & & 56 & 001344 VIB & $£ 1,310$ \\
\hline
\end{tabular}

Page 26 of 26 